\title{
Collection of Group Characteristics of Pleurotus Eryngii Using Machine Vision
}

\author{
Yunsheng Wang ${ }^{1}$, Changzhao Wan ${ }^{1}$, Juan Yang ${ }^{1}$, Jianlin Chen ${ }^{1}$, Tao Yuan ${ }^{1}$, \\ and Jingyin Zhao ${ }^{1,2}$ \\ ${ }^{1}$ Technology \& Engineering Research Center for Digital Agriculture, \\ Shanghai Academy of Agriculture Sciences, Shanghai, P.R. China 201106 \\ ${ }^{2}$ No.2901 Beidi Road, Shanghai, 201106, P.R. China, \\ Tel.: +86-21-62204989 \\ wys188@163.com
}

\begin{abstract}
An information collection system which was used to group characteristics of pleurotus eryngii was introduced. The group characteristics of pleurotus eryngii were quantified using machine vision in order to inspect and control the pleurotus eryngii house environment by an automated system. Its main contents include the following: collection of pleurotus eryngii image; image processing and pattern recognition. Finally, by analysing pleurotus eryngii image, the systems for group characteristics of pleurotus eryngii are proved to be greatly effective.
\end{abstract}

Keywords: Pleurotus eryngii, Group characteristics, Machine vision, Collection.

\section{Introduction}

World's edible fungi output reached 13 million tons at 2006, China is the largest producer of edible fungi, edible fungi production in China is the world's edible fungi production for more than $70 \%$. Agricultural production in China, the sixth production of edible fungi, edible fungi have become the pillar industries in the agricultural economy (Huang Chienchun, 2006; Lu Min, 2006).

At present, the small-scale, extensive management production of edible fungi in China is still the main form, although this mode of production and low cost initial investment, but subject to natural risks and market risks is very weak, it is difficult to guarantee product quality, production efficiency is very low. Therefore, the industrialization and standardization of edible fungi production has become the development direction of edible fungi industry.

In the early 1990s, China has introduced several edible fungi production line, so that productivity increased a hundredfold, after nearly 20 years of practice and exploration, China has gradually developed a model of development of mushroom industry.

Edible fungi production in factories, we find that the edible fungi cultivation of industrial technology as the core, "Mushroom house climate control system" continues to experience-based control, far from being done in accordance with the edible fungi production automation features of the Tracking control. Edible Fungi groups

\footnotetext{
${ }^{*}$ Corresponding author.
} 
uniformity and the uniform shape and other characteristics of indicators, industrial cultivation of edible fungi has been the main basis for control measures. For the current status of these indicators of edible fungi in the diagnosis of a major in mind the number of measurements and visual way, there is a slow investigation, the charges, subjective strong, and the error of defects, and some features were also difficult to describe in considerable Restrictions on the extent of the industrial production of edible fungi in time during the strain of scientific management, industrial production of edible fungi is present on the "bottleneck" problem. Therefore, exploration accurate and rapid collection of edible fungi groups feature of the new methods, carefully observe the growth of edible fungi minor changes, summed up the seasons, days and nights change on the growth of edible mushrooms, edible fungi to establish the best model of environmental control So that the quality of edible mushroom cultivation factory stability, cultivation and management of fully automated intelligent, and machine vision technology in the industrial production of edible fungi in the show great potential for application.

Machine vision research using computers to simulate the visual function of things from an objective image to extract information, be understood to be processed and eventually used for the actual detection, measurement and control. Machine vision technologies, including image acquisition, image processing and pattern recognition, machine vision can be simulated by the human eye to the edible mushrooms to the close-up photography visible spectrum, and then use artificial intelligence, digital image processing techniques to analyze the image information, access to research Object required information.

\section{Related Research}

The use of machine vision technology feature extraction Mushroom has undertaken a number of studies, the representativeness of the research results:

(Van De Voo ren et al., 1992) The use of machine vision technology to determine morphological characteristics of a variety of mushrooms, Circularity, Bending Energy, Sphericity and Eccentricity and so on to describe the the shape of the characteristics of mushrooms; (Yu GaoHong et al., 2005) Identification of the use of machine vision algorithms for contour description of the individual mushroom; (Vízhányó et al., 1998) color image analysis of edible fungi of the mechanical damage in the color and different color sick to to maximize the commercial value; (Tünde, et al., 2000) The use of image enhancement algorithm to distinguish between diseases of the color difference between edible fungi; (Heinemannp et al., 1994) The use of machine vision technology for classification of edible fungi; (NJ Kusabs et al., 2006), such as the use of machinery vision technology from a number of morphological parameters for grading of edible fungi; (Van Loon et al., 1996) The use of machine vision to detect the mushroom the size of individual developmental stages; (Tillett et al., 1989) in the edible mushroom harvesting machines use machine vision to locate Mushroom; (Tillett et al., 1991) of the edible fungi mushroom bed positioning algorithm; (Reed et al., 1995) The use of machine vision to identify the mushroom mushroom harvest size.

Study on the application of machine vision are mostly limited to simple, idealized monomer, the complex problem of overlapping research groups small, and the growth 
of the state of the monomer can not accurately reflect the actual population growth of the law can not be used to guide production management practices. Characteristics of the identifiable group because of its image with a lot of interference factors for image segmentation and feature extraction very difficult, very difficult to identify, and thus need to study more efficient segmentation algorithm based on feature extraction, as the demand for the development of applications depth, machine vision technology will be gradually applied to the recognition of group identities.

\section{System Introduction}

\subsection{System Design}

Precise control through the small environment the production of pilot experiments with the factory-based, as the leading machine vision technology, neural networks, machine learning as the link for example, integrated expert system and a variety of mushroom production technology and methods, and make full use of mushroom production expertise to achieve the characteristics of the smart machine groups mushroom identification and diagnosis of mushroom growth of the state of the technological breakthrough.

The overall technology map as shown in Fig.1

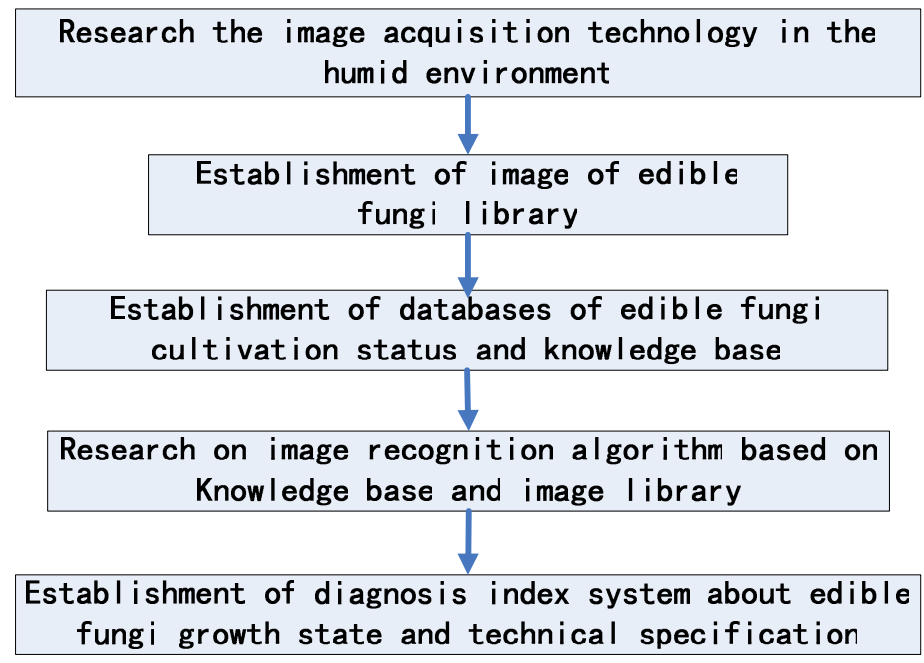

Fig. 1. Overall technology map

\subsection{Research Methods and the Implementation of the Program}

The implementation of the program in Fig. 2

(1) Study the characteristics of pleurotus eryngii, the establishment of a wealth of examples of environmental test samples of small rooms, as a group of image characteristics and growth of information, data access to sources of information. Controlled trial of small environment, including different temperature, humidity, $\mathrm{CO} 2$ 
concentration to deal with. Industrial production of samples, including groups of as many as possible samples of the edible fungi. Through a rich mushroom habitat type and sample number of learning samples, to improve the accuracy of the machine to identify and enhance the applicability of the future to build systems.

(2) Pleurotus eryngii groups to carry out multi-dimensional space-time image data acquisition. pleurotus eryngii with cameras in key growth period, from the top, middle and base in different parts of using down, up, at eye level groups depending on the perspective of image; used traditional method homogeneous simultaneous determination of edible fungi and pleurotus eryngii covered neatly color, strength and other characteristics of growth examples of learning data, and invited experts in edible fungi pleurotus eryngii growth of the state assessment; the establishment of pleurotus eryngii growth of the state information database.

(3) Image feature extraction, image feature database to establish. To obtain images of pleurotus eryngii pretreatment to remove noise; to degradation caused by the phenomenon of recovery. The use of morphological operators and Hough transform techniques for the separation characteristics. Pleurotus eryngii growing in view of different culture production is based on different indicators, the growth of edible fungi in the group stage of the growth characteristics and state indicators to be classified by level of importance to determine the main objectives. Comprehensive application of

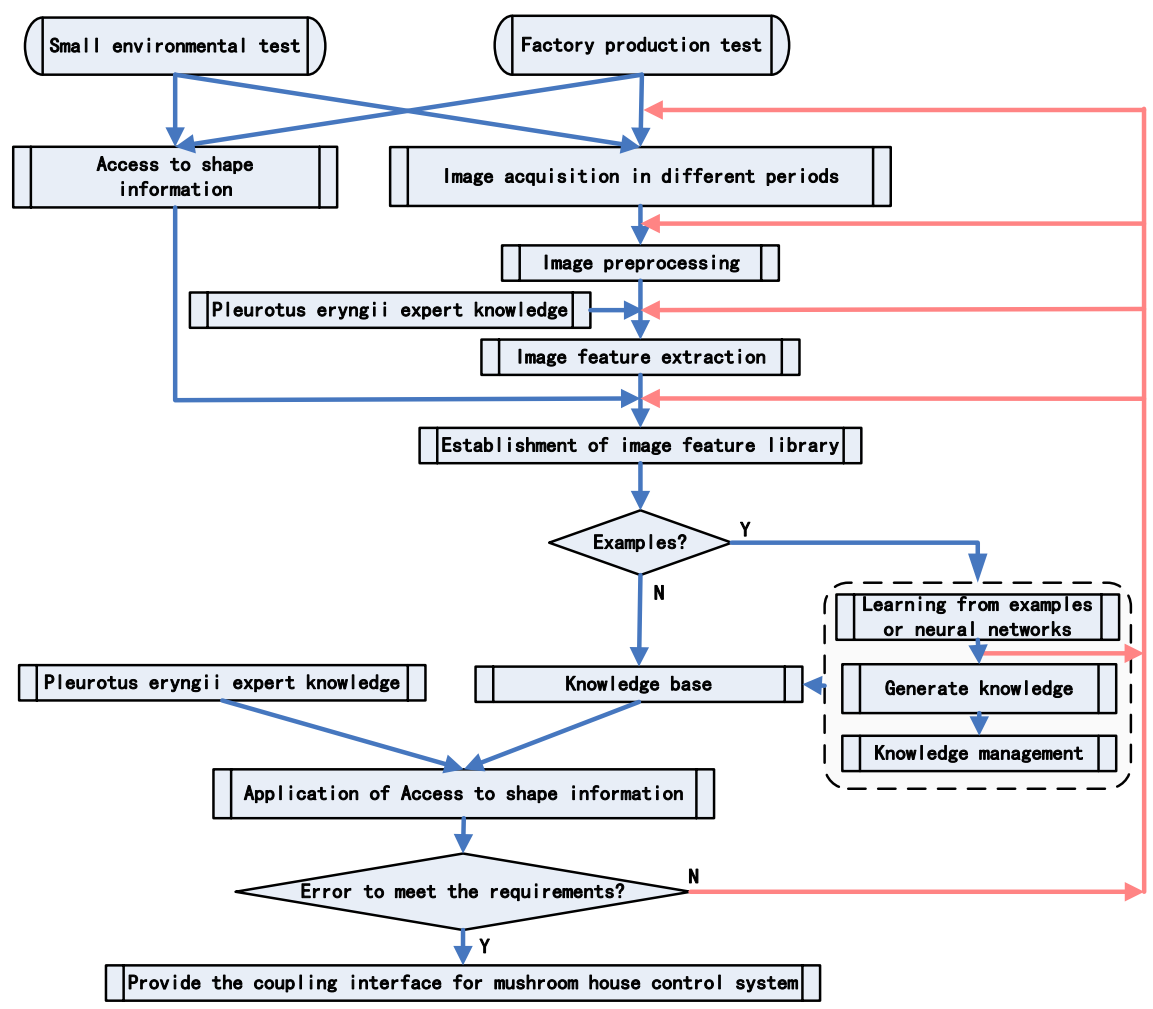

Fig. 2. Groups the characteristics of acquisition and pleurotus eryngii growth of the state of rapid diagnostic technology map 
image recognition, neural networks, machine learning from examples, such as fuzzy mathematical algorithm to be addressed, and through comparison, the screening, to determine the optimal algorithm. Difficult for some of the characteristics of image recognition, will take full advantage of the experience of mushroom experts, in order to relax the requirements of machine vision technology.

(4) Summary of mushroom factory production management knowledge and experience to create the rules, the establishment of image recognition applications knowledge.

(5) Characteristics of groups in the pleurotus eryngii image acquisition, intelligent identification on the basis of the establishment of sets of machine vision technology in pleurotus eryngii growth of the state of diagnosis index system and technical specifications.

\section{System Characteristics and Prospects}

System is to be used in machine vision technology to identify intelligence mushroom groups and growth characteristics of the state of the practice of rapid diagnosis of an attempt to change the traditional mushroom factory groups characterized by the production of visual and manual collection method to enable automatic environmental control mushroom house intelligent.

Research based on the factory production process of edible fungi on mushroom growing demand for dynamic monitoring, application prospects, raise the level of mushroom factory production management.

\section{Acknowledgements}

This study was supported by National Key Technology R\&D Program (NO.2006 BAD10A11), Shanghai Municipal Science and Technology Commission Project (073919103) and Shanghai Municipal Science and Technology Commission project (08DZ2210600).

\section{References}

Gunasekaran, S., Cooper, T., Berlage, A.G., et al.: Image processing for stress cracks in corn kernels. Transactions of the American Society of Agricultural Engineers (1), 266-271 (1987)

Heinemann, H., Hughesr, Morrow, C., et al.: TGrading of mushrooms using a machine vision system. Transactions of the ASAE 37(5), 1671-1677 (1994)

Humphries, S., Simonton, W.: Identification of plant pans using color and geometric image data. Trans of the ASAE 36(5), 1493-1500

Felfdi, J., Szepes, A.: Machine Vision Based Quality Assessment of Fruits and Vegetables. In: Proceedings of the World Congress of Computers in Agriculture and Natural Resources, pp. 42-48 (2002)

van de Vooren, J.G., Polder, G., Van der Heijden, G.W.A.M., et al.: Application of image analysis for variety testing of mushroom. Euphytica 57(3), 245-250 (1991)

Reeda, J.N., Milesa, S.J., Butlera., J., et al.: AE-Automation and Emerging Technologies Automatic Mushroom Harvester Development. Journal of Agricultural Engineering Research 78(1), 15-23 (2001) 
Kacira, M., ling, P.P.: Design and development of an automated and non-contact sensing system for continuous monitoring of plant health and growth. Trans of the ASAE 44(4), 989-996 (2001)

Ling, P.P., Kuzhitsky, V.N.: Machine vision techniyucs for measuring the canopy of tomato seedling. Journal of Agricultural Enginccring Itescarch 65(2), 85-95 (1996)

Marchant, J.A., Ongungo, C.M., Street, M.J.: Computer vision for potato inspection without singulation. Computers and Electronics in Agriculture (4), 235-244 (1990)

Morimoto, T., Hashimoto, Y.: AI approaches to identification and control of total plant production for SPA\&SFA to environmental control. In: 3rdIFAC/CIGR workshop on artificial intelligence in Agriculture, pp. 1-20 (1998)

Kusabs, N.J., Trigg, L., Bollen, A.F., Holmes, G.: Objective measurement of mushroom quality relative to industry inspectors. International Journal of Postharvest Technology and Innovation 1(2), 189-201 (2006)

Reed, J.N., Crook, S., He, W.: Harvesting mushrooms by robot. In: Science and cultivation of edible fungi, pp. 385-391 (1995)

Seginer, I., Elster, R.T., Goodrum, J.W., et al.: Plantwilt detection by computer vision tracking of leaftips. Transactions of the ASAE 36(5), 1563-1567 (1992)

Shimizu, H., Hcins, R.P.: Computer vision based system for plant growth analysis. Transaction of the ASAE 38(3), 959-964 (1995)

Tarbcll, K.A., Rcid, J.F.: A computer vision system for characteriziug corn growth and development. Transaction of the ASAE 31(5), 2215-2255 (1991)

Tillett, R.D.: Image analysis for agricultural processes: a review of potential opportunities. J. Agric. Engng. Res. 50, 247-258 (1991)

Tillett, R.D., Batchelor, B.G.: An algorithm for locating mushrooms in a growing bed. Comp. Electron. Agric. 6(3), 191-200 (1991)

Tillett, R.: Locating mushrooms for robotic harvesting, SPIE Conference on J. Non-destructive crop mcasurentents by image processing for crop growth control. Journal of Agricultural Engineering Research 61(2), 97-105 (1995)

Van Loon, P.C.C.: Het bepalen van het ontwikkelingsstadium bij dechampignon met computer beeldanalyse. Champignoncultuur 40(9), 347-353 (1996)

Vízhányó, Tillett, R.D.: Analysis of mushroom spectral characteristics. In: Proceedings of AgEng 1998 International Conference on Agricultural Engineering, pp. $24-27$ (1998)

Woebbeckc, D.M.M., Von Bargen, K., et al.: Shape features for identifying young weeds using image analysis. Transaction of the ASAE 38(1) (1995); Intelligent Robots and Computer Vision VIII, 260-269 (1989)

Trooien, T.P., Hermann, D.F.: Measurement and simulation of potato leaf area using image processing. Transactions of the ASAE 35(5), 1719-1721

Trooieu, T.P., Hermann, D.F.: Measurement and simulaticm of Ilotato leaf area using image processing (II) Model development. Transaction of the ASAE 35(5) (1992)

Tünde, Vízhányó, Felfldi, J., et al.: Enhancing colour differences in images of diseased mushrooms. Computers and Electronics in Agriculture 26(2), 187-198 (2000)

Van De Vooren, J. G., Polder, G., et al.: Identification of mushrooms cultivars using image analysis. Transactions of the ASAE 35(1), 347-350 (1992)

Wolfe, R.R., Swaminathan, M.D.: Determining orientation and shape of bell peppers of machine vision. Transactions of the American Society of Agricultural Engineers (6), 1853-1856 (1987)

GaoHong, Y., Yun, Z., Ge, L., et al.: Transactions of the Chinese Society of Agricultural Engineering 21(6), 101-104 (2005) 